\title{
Um sonho ecológico para a Igreja: - magistério de Francisco da Laudato Si' ao Sínodo para a Amazônia
}

\author{
An ecological dream for the church: \\ the magistery of Francis from Laudato $\mathrm{Si}^{\prime}$ \\ to the Synod for the Amazon
}

José Reinaldo F. Martins Filho

\begin{abstract}
Falta-lhes, pois, uma conversão ecológica, que comporta deixar emergir, nas relações com o mundo que os rodeia, todas as consequências do encontro com Jesus. Viver a vocação de guardiões da obra de Deus não é algo de opcional nem um aspecto secundário da experiência cristã, mas parte essencial duma existência virtuosa. ${ }^{1}$
\end{abstract}

\section{Resumo}

O presente texto tem por objetivo abordar a questão ecológica a partir da importância que esse tema conquistou junto ao pontificado de Francisco. Para isso, toma como ponto de discussão a relação entre a Encíclica Laudato Si' e o Sínodo da Amazônia, considerando, particularmente, o Documento Final do Sínodo e a Exortação Apostólica Pós-Sinodal Querida Amazônia. Como principais contribuições, pretende-se, por um lado, evidenciar a ecologia como foco para o alargamento de um olhar que envolverá o diálogo inter-religioso e a cooperação internacional. Por outro, quer salientar que a ênfase ecológica

${ }^{1}$ LS 217. 
extraída do Sínodo Amazônico também contribui para a introdução de novos modelos eclesiais, com ênfase para a dimensão sinodal; além de rediscutir o papel e a posição do ser humano na criação.

Palavras-chave: Ecologia. Papa Francisco. Laudato Si'. Querida Amazônia. Sínodo dos Bispos.

\begin{abstract}
This text aims to address the ecological issue from the importance that this theme has achieved with Francis's pontificate. For this, it takes as a point of discussion the relationship between the Encyclical Laudato Si' and the Synod of the Amazon, considering, particularly, the Final Document of the Synod and the Post-Synodal Apostolic Exhortation Querida Amazonia. As main contributions, it is intended, on the one hand, to highlight ecology as a focus for broadening a view that will involve interreligious dialogue and international cooperation. On the other hand, to emphasize that the ecological emphasis extracted from the Amazon Synod also contributes to the introduction of new ecclesial models, with emphasis on the synodal dimension; in addition to re-discussing the role and position of human beings in creation.
\end{abstract}

Keywords: Ecology. Pope Francis. Laudato Si’. Querida Amazônia. Synod of Bishops.

\title{
Introdução
}

Uma aproximação entre Teologia e Ecologia pode se dar por diferentes caminhos, seja pela via bíblica, por exemplo, enfatizando um dos relatos da criação, ou, talvez, a partir da Antropologia Teológica, numa leitura de ser humano que se atente para o estreito vínculo entre a natureza humana e o meio de vida que a circunda e sustenta. No entanto, também é inegável o potencial dado a este tema a partir das reflexões exaradas do magistério de Francisco. Desde o início de seu pontificado, o papa tem insistido na urgência em se retomar uma discussão a respeito da vida de maneira mais profunda, considerando as relações entre os ecossistemas e a presença do homem na Terra, como condição de possibilidade para essa permanência. Todos podemos 
observar como a questão ecológica se tornou patente em diferentes setores da comunidade humana, em nível internacional ou local, seja para apontar os limites de uma concepção de mundo pautada pela exploração incontida, seja para reunir forças em prol de remediar a crise que já se encontra em curso. A Teologia, desse modo, não estaria fora de semelhante cooperação, acrescentando sua parcela de contribuição nos debates e, no caso do Papa Francisco, compondo uma ação coordenada junto a outras forças internacionais, chamando a atenção e dando visibilidade ao tema.

Entre outras tentativas, esse argumento se sustenta a partir da Carta Encíclica Laudato Si', publicada em 24 de maio de 2015. Pela primeira vez na história um documento magisterial destinou-se especificamente à promoção do debate socioambiental. Por um lado, como uma forma de resgate da inspiração original do governo pastoral de Francisco, colhida do testemunho do poverello d'Assisi - do qual herdara não somente o nome, mas todo um projeto de vida. ${ }^{2}$ Por outro, não podemos deixar de mencionar que possivelmente se trata do documento pontifício que mais profundamente marcou a época moderna, sobretudo extraeclesialmente, influenciando debates no mundo das ciências, fomentando iniciativas por parte de governos de diversos países, aproximando religiões na construção de iniciativas comuns. Isso não sem, também, suscitar reações contrárias. Muitos, sem dúvida, prefeririam uma Encíclica dedicada a alguma questão de fé, talvez uma explanação sobre os limites da sociedade contemporânea na busca pelo sagrado, ou o aprofundamento sobre alguma prática de piedade baseada na mística cristã. Embora, contudo, tais questões também demandem legítima atenção por parte da Teologia, Francisco optou por outro caminho: o de relacionar a vivência da fé e a inseparabilidade da ação concreta que dela deve resultar. Assim, ao ancorar-se na questão ecológica, apontou-nos e continua a nos apontar um dos temas de maior importância para o tempo presente, inserindo a discussão sobre o futuro do cristianismo dentro de uma perspectiva ainda não explorada.

O movimento iniciado pela Laudato Si', porém, não cessou com os impactos alcançados pelo documento. Como pretendo sustentar no que segue,

\footnotetext{
${ }^{2}$ Isso aparece no LS 10, quando o papa convoca a figura de Francisco de Assis como modelo a ser seguido pelos cristãos no mundo de hoje: "Acho que Francisco é o exemplo por excelência do cuidado pelo que é frágil e por uma ecologia integral, vivida com alegria e autenticidade. É o santo padroeiro de todos os que estudam e trabalham no campo da ecologia, amado também por muitos que não são cristãos. Manifestou uma atenção particular pela criação de Deus e pelos mais pobres e abandonados. Amava e era amado pela sua alegria, a sua dedicação generosa, o seu coração universal".
} 
existe uma forte relação entre a proposta iniciada pelo texto de 2015 e a convocação do Sínodo da Amazônia, em 15 de outubro de 2017, especialmente com vistas ao seu tema geral, a saber: Amazônia, novos caminhos para a Igreja e para uma Ecologia integral. Dito de outra maneira, não é mais possível dissociar os novos caminhos para a Igreja de sua inserção concreta no debate sobre o aguçamento da crise socioambiental. Se em outros tempos nos limitávamos a pensar o homem segundo o seu estatuto de singularidade, como se este pudesse se apartar do meio ambiente em que vive e desenvolve a vida, atualmente não é mais admissível tomar isoladamente o universo das relações humanas, como se essas fossem desconexas da realidade em que estão inseridas. Nesse âmbito, a natureza, entendida de forma orgânica e sistemática possui um significado particularmente importante. Trata-se de repensar o papel desempenhado pelo ser humano junto à obra criadora de Deus: não o devastador, mas o cuidador de todas as criaturas. A questão da ecologia integral deve, então, assumir a centralidade das discussões eclesiais, de modo que uma articulação entre Teologia e Ecologia - questões ecológicas ou socioambientais, para mantermos um leque ainda mais amplo - não é apenas possível, mas sumamente necessária. ${ }^{3}$ Isso aprendemos sobretudo do magistério de Francisco e, mais recentemente, da discussão emanada do Sínodo Especial para a Região Amazônica. O texto a seguir representa, portanto, a tentativa de diálogo tanto com a Encíclica Laudato Si', como representante da discussão ambiental em termos eclesiais mais recentes, quanto com os documentos do Sínodo dos Bispos, realizado em outubro de 2019 em Roma - com o objetivo de discutir novos caminhos pastorais para a Igreja amazônica e, ao mesmo tempo, novas formas de colaboração para a construção de uma ecologia integral. Assim, quem sabe nos seja possível estabelecer o perfil ecológico do apostolado de Francisco e, mais que isso, colaborar na consolidação de espaços de discussão qualificada sobre o tema, cuja urgência não nos permite retroceder.

\section{O caminho sinodal como esforço ao diálogo}

De forma semelhante a outros sínodos da Igreja - especialmente os realizados nas últimas décadas, sempre dedicados a temas de atualidade para a comunidade cristã católica como um todo - o Sínodo Especial para a

\footnotetext{
${ }^{3}$ Esse assunto também foi recentemente discutido por outros intérpretes, como ALMEIDA, N. M.; BRIGHENTI, A., Sínodo da Amazônia.
} 
Amazônia também partiu de uma escuta atenta da realidade local, com intensa participação de todas as dioceses pertencentes à Rede Eclesial Pan-Amazônica (REPAM). Aliás, o verbo "escutar", em suas diferentes conjugações, pode ser apontado como um dos que mais insistentemente aparecem ao longo de todo o Documento Final do Sínodo para a Amazônia, como quando se fala em "escutar a voz da Amazônia", em "escutar a voz dos povos", em "escutar o clamor do território" e, enfim, em "escutar a voz do Espírito" - sempre a fim de respondê-la com nossa iniciativa total. Desse modo, paralelamente a outros temas - e, talvez, de forma ainda mais destacada que os demais - a questão ecológica também compareceu por diferentes vias, o que não poderia ser diferente num Sínodo cujo foco se dirige a um dos ecossistemas mais importantes do planeta, responsável pela manutenção do ciclo das chuvas e pelo equilíbrio do clima em diferentes regiões. ${ }^{4}$ Isso é o que pode ser visto, por exemplo, no que se encontra no n. 23 do Instrumentum Laboris, enviado pelas conferências episcopais Boliviana e Venezuelana, respectivamente: "A selva não é um recurso para explorar, é um ser ou vários seres com os quais se relacionar"; "Amargura-nos a destruição da natureza, a destruição da selva, da vida, de nossos filhos e das gerações vindouras". ${ }^{5}$ Ambos estes fragmentos foram retirados das remissivas em resposta às provocações do próprio Papa Francisco, quando em visita a Puerto Maldonado, em 19 de janeiro de 2018. Conforme suas próprias palavras: "A cultura do descarte é uma cultura anônima, sem laços, nem rostos. Uma cultura sem mãe, que só quer consumir. A terra é tratada dentro desta lógica. As florestas, os rios e as torrentes são aproveitados, utilizados até ao último recurso, e depois deixados como baldios e inúteis. As próprias pessoas são tratadas com esta lógica". ${ }^{6}$ Basta-nos esse argumento como prova de que a discussão ambiental, tão amplamente explorada pelo Instrumentum Laboris, pelo Documento Final do Sínodo e, por fim, pela Exortação Apostólica Pós-Sinodal Querida Amazônia, não pode ser levada adiante sem que uma dupla ênfase seja posta: em primeiro lugar, a participação das comunidades culturais autóctones, isto

\footnotetext{
${ }^{4}$ A constatação da importância do bioma amazônico para o planeta é mencionada por Francisco em sua Exortação: “O equilíbrio da terra depende também da saúde da Amazónia. Juntamente com os biomas do Congo e do Bornéu, deslumbra pela diversidade das suas florestas, das quais dependem também os ciclos das chuvas, o equilíbrio do clima e uma grande variedade de seres vivos. Funciona como um grande filtro do dióxido de carbono, que ajuda a evitar o aquecimento da terra" (Querida Amazônia, 48).

${ }^{5}$ SÍNODO DOS BISPOS, Instrumentum Laboris, 23.

${ }^{6}$ FRANCISCO, PP., Encontro com a população.
} 
é, dos diversos povos originários, entre os quais os indígenas, os ribeirinhos, os sobreviventes da floresta como um todo, cuja palavra deve se tornar cada vez mais acessível; em segundo lugar, uma leitura da pessoa humana inserida no seu meio de vida e sobrevivência, alargando o olhar sobre as condições territoriais, de fauna e flora, de diversidade de etnias e tradições, a partir do critério da relacionalidade e da integração. O modelo verticalizado, que tem o ser humano como ponto alto do vértice da dignidade, levou-nos à destruição desmedida, ao uso da criação para nossas finalidades particulares. Inspirado na discussão iniciada pela Laudato Si', Francisco quer novamente colocar os olhos da Igreja sobre a questão ecológica, mostrando sua potência rumo a uma concepção eclesial e humana mais profunda.

Este, em suma, parece ser o propósito que motivou todo o processo sinodal, desde a sua convocação e, certamente, também durante a sua realização em Roma. Prova disso é o clima de fraternidade que povoou o desdobramento dos trabalhos, com participação ativa do papa, de cardeais e bispos e de um expressivo grupo de representantes dos povos amazônicos em sua pluralidade: quilombolas, indígenas, ribeirinhos, missionários e missionárias, advindos dos nove países integrantes da REPAM. É o que transparece no relato de Agenor Brighenti, presbítero brasileiro que participou como perito do Sínodo: "Eram 186 padres sinodais, acompanhados de mais de uma centena de pessoas, em especial indígenas e mulheres, em uma harmônica sinfonia de Igrejas e povos preocupados com o evangelho da vida e o cuidado da "Casa Comum".' ' Semelhante clima de esperança impulsionava as várias comunidades católicas espalhadas pela Amazônia, que com suas preces nutriam o desenvolvimento do Sínodo. Também o olhar do mundo exterior pôde atestar a importância que o tema alcançou em debates junto a importantes organismos mundiais, como é o caso da Organização das Nações Unidas (ONU). Apesar de tanta repercussão positiva, contudo, também não podemos descartar as diversas reações que se demonstraram contrárias ao evento, quer advindas do contexto intraeclesial, quer de fora dos limites da catolicidade. ${ }^{8}$ Não é segredo para ninguém a forte reação existente contra as ações de Francisco, especialmente no que sugere certa renovação pastoral da Igreja e a introdução de temas considerados excepcionalmente novos. Para

\footnotetext{
${ }^{7}$ BRIGHENTI, A., O Sínodo da Amazônia, p. 593.

${ }^{8}$ SILVEIRA, E. J. S.; REIS, M. V. F.; ALMEIDA, F. P. M., O Sínodo da Amazônia e os dilemas do Catolicismo.
} 
muitos, o papa insiste em assuntos que ultrapassam a sua competência, e, em termos não-organizacionais da estrutura eclesial, a questão ecológica é, provavelmente, o maior foco de conflitualidade.

Começando pelo contexto ad extra, não podemos negar a reação altamente negativa de alguns governos nacionais dos países envolvidos no Sínodo, entre os quais o Brasil é certamente o exemplo que ganhou maior notoriedade particularmente por conta das constantes queimadas propaladas pelo território amazônico justamente às vésperas do Sínodo, em 2019. São-nos igualmente presentes os diversos pronunciamentos públicos de integrantes do governo brasileiro a respeito do evento, em um dos casos até mesmo mencionando a mobilização da Agência Brasileira de Inteligência (ABIN) como forma de resguardar o que entenderam como ameaça à soberania nacional. ${ }^{9}$ Tal leitura foi altamente reforçada pelos diferentes movimentos neopentecostais, com presença avassaladora na Amazônia, como forma de enfraquecer o significado do Sínodo para o mundo em geral. Por sua inserção no combate de desigualdades e injustiças sociais, com forte atuação na luta pela demarcação de terras indígenas, na regularização fundiária de pequenos agricultores, na assistência aos mais pobres, especialmente aos migrantes (como é o caso de Roraima, desde o agravamento da crise na Venezuela), a Igreja na Amazônia conquistou a repulsa por parte de hegemonias das mais diferentes ordens. Tal embate ganha contornos cada vez mais acirrados, na medida em que poderes políticos se alinham ao lado dos que querem a destruição da floresta. Recentemente, ao ser interpelado sobre o lançamento da Encíclica PósSinodal Querida Amazônia, o presidente da Conferência Nacional dos Bispos do Brasil (CNBB) e arcebispo de Belo Horizonte, Dom Walmor Oliveira de Azevedo, afirmou que a Igreja no Brasil permanece contrária a "tudo aquilo

\footnotetext{
${ }^{9}$ Em janeiro de 2019, o senador brasileiro Humberto Costa, em discurso junto à tribuna do Senado da República, repudiou o uso da Agência Brasileira de Inteligência (ABIN) como forma de temorizar agentes pastorais, padres e bispos ligados à organização e realização do Sínodo da Amazônia - fato confirmado pelo próprio presidente da república em exercício. A matéria é publicada no site do Senado (SENADO FEDERAL, Humberto Costa critica interferência da Abin na Igreja Católica). Esse pronunciamento, bem como outras manchetes em diferentes jornais brasileiros obrigaram a ABIN a se manifestar em nota, o que ocorreu em 10 de fevereiro do mesmo ano, negando ter bispos sobre investigação, embora admitisse a existência de "preocupação funcional do Ministro Chefe de Estado do Gabinete de Segurança Institucional com alguns pontos da pauta do Sínodo sobre a Amazônia" que ocorreria em Roma. Um pouco adiante a mesma nota reforça que "parte dos temas do referido evento tratam de aspectos que afetam, de certa forma, a soberania nacional" (AGÊNCIA BRASILEIRA DE INTELIGÊNCIA, Nota de Esclarecimento).
} 
que prejudica o meio ambiente e os povos nativos", opondo-se, igualmente, "àquilo que atinge e que se faz por interesse meramente econômico, em um desenvolvimentismo que não atende às necessidades dos mais pobres, mas, pelo contrário, os exclui". ${ }^{10}$ Atitude semelhante foi adotada pelo atual arcebispo de Manaus, Dom Leonardo Ulrich Steiner. Enfim, a respeito das diferentes visões sobre a questão ecológica e, especialmente, sobre iniciativas de proteção da Amazônia, também não podemos deixar de mencionar o recente pronunciamento do presidente da república do Brasil, senhor Jair Messias Bolsonaro, rechaçando uma mensagem divulgada pelo Papa Francisco em que dizia que "a Amazônia é de todos". ${ }^{11}$ Como vemos, trata-se de um tema delicado, com significativos impactos sobre o cenário político, econômico e cultural, o que novamente reforça a importância de sua discussão e da extensão desse diálogo para fora das barreiras meramente institucionais do catolicismo.

De outra parte, intraeclesialmente, alguma reação também foi sentida, seja por parte de bispos cujo conservadorismo é conhecido, movimentos eclesiais de inclinação pré-conciliar ou ligados à Renovação Carismática Católica (RCC), indo, até mesmo, às constantes oposições demonstradas ao longo do mês de outubro de 2019 , consecutivamente à realização das aulas sinodais. Podemos, à guisa de ilustração, evocar o furto e consequente descarte no rio Tibre da imagem da Pachamama, levada por um grupo de indígenas latinos e utilizada nalguns dos rituais inter-religiosos paralelamente ao Sínodo - obrigando o próprio Papa Francisco a emitir um pedido público de desculpas. ${ }^{12}$ Como motivação para gestos como esse, está o que alguns defendem como o exagero idolátrico da natureza, posta acima de outros pontos considerados fundamentais para a autocompreensão que o cristianismo

\footnotetext{
${ }^{10}$ Trecho retirado de matéria publicada no jornal Estadão, do dia 12 de fevereiro de 2020 (FRAZÃO, F., CNBB vai na "contramão" de propostas de governo Bolsonaro).

${ }^{11}$ Conforme noticiado no dia 13 de fevereiro de 2020, pelo jornal Correio Brasiliense, o presidente da república, Jair Bolsonaro, teria criticado o texto do Papa Francisco depois que o pontífice pediu a proteção da floresta amazônica. Bolsonaro também teria alfinetado ambientalistas frente aos incêndios na Austrália: "Não pega fogo floresta úmida. Ninguém fala na Austrália. Pegou foco na Austrália toda, ninguém fala nada. Cadê o Sínodo da Austrália? O Papa Francisco falou ontem que a Amazônia é dele, do mundo, de todo mundo" (SOARES, I., Bolsonaro critica texto do Papa).

${ }^{12}$ Por ocasião do acontecido, as palavras do papa foram: "gostaria de dizer uma palavra sobre as estátuas da Pachamama, que foram retiradas da Igreja Santa Maria in Transpontina [sic], que estavam lá sem intenções idólatras e foram jogadas no Tibre". E seguiu: "como bispo da Diocese, peço perdão às pessoas que se foram ofendidas com esse gesto [sic]" (A12 REDAÇÃO, Papa Francisco fala sobre imagens jogadas no Rio Tibre).
} 
deveria possuir de si mesmo. Seja como for, a questão ecológica também é importante para o desvelamento de um cenário plural internamente à Igreja Católica, com matizes que variam do enfrentamento menos explícito até a absoluta recusa. Nesse sentido, também é curioso como no Sínodo da Amazônia o debate ecológico venha acompanhado da insistência, por parte de Francisco, na descoberta de uma nova eclesiologia, fundamentalmente sinodal, para a qual as respostas apenas surgirão do caminho conjunto, mas sempre considerando a validade dos que falam a partir da própria realidade em que vivem. Mais que isso, como alude o papa no n. 105 da Exortação Pós-Sinodal, a realidade socioambiental também "desafia-nos a superar perspectivas limitadas, soluções pragmáticas que permanecem enclausuradas em aspectos parciais das grandes questões, para buscar caminhos mais amplos e ousados"13 - dos quais até agora talvez passássemos ao largo. Este é o sentido do que Francisco chamou de conversão integral, tema que é abordado tanto pela Laudato $S i$ ', recorrendo ao já anunciado pelo magistério mais recente no século XX, mas, de forma ainda mais pontual, dos resultados apresentados pelo Documento Final do Sínodo para a Amazônia.

\section{Rumo a uma conversão ecológica integral}

Fiel à sua missão de transmitir a verdade do Evangelho aos povos, a Igreja jamais pôde desconsiderar a sua necessidade de constante conversão. Mais recentemente, isso ficou claro pela opção de São João XXIII, de tão feliz memória, de realizar o primeiro anúncio sobre sua intenção de convocar um Concílio universal e ecumênico da Igreja justamente na Festa litúrgica da conversão de São Paulo. ${ }^{14}$ Passadas várias décadas, mas mantendo o mesmo espírito de continuidade e colaboração, ao falar pela primeira vez em conversão ecológica, Francisco quis valer-se das palavras de São João Paulo II, ainda em sua primeira encíclica, Redemptor hominis, em cujo n. 15 dizia: "[...] o homem parece muitas vezes não dar-se conta de outros significados do seu ambiente natural, para além daqueles que somente servem para os fins de um uso ou consumo imediatos. Quando, ao contrário, era vontade do Criador que o homem comunicasse com a natureza como 'senhor' e 'guarda'

\footnotetext{
${ }^{13}$ Querida Amazônia, 105.

${ }^{14}$ JOÃO XXIII, PP., Allocuzione del Santo Padre Giovanni XXIII con la quale annuncia il Sinodo Romano, il Concilio Ecumenico e l'aggiornamento del Codice di Diritto Canonico.
} 
inteligente e nobre, e não como um 'desfrutador'". ${ }^{15}$ Tratando-se, então, de retomar o caminho da liberdade humana, pautada pelo reconhecimento de uma relacionalidade inextirpável com o meio ambiente, que dá condições e favorece a continuidade da obra criadora de Deus, falar em conversão requer abertura e diálogo, o que o Instrumentum Laboris do Sínodo da Amazônia definiu da seguinte maneira: "O processo de conversão ao qual a Igreja é chamada implica desaprender, aprender e reaprender". ${ }^{16}$ Aliás, já as primeiras páginas do mesmo Instrumentum Laboris recordam a insistência com que o pontificado de Francisco tem solicitado da Igreja a capacidade de converterse: seja a conversão pastoral (com relevância para o que se encontra na Exortação Apostólica Evangelii Gaudium, de 2013), ${ }^{17}$ a conversão sinodal (conforme exposta pela Episcopalis Communio, sobre o Sínodo dos Bispos, de 2018) ${ }^{18}$ ou, enfim, a conversão ecológica (apresentada de maneira mais radical e enfática na Laudato $S i^{\prime}$ ). ${ }^{19}$ É, ao mesmo tempo, iluminador como o Documento Final do Sínodo falou em conversão a cada novo capítulo, insistindo neste ponto em sua ênfase sobre a pastoral, a cultura, a sinodalidade eclesial e, de forma particular, a ecologia. ${ }^{20}$

Embora todo esse documento - o qual o Papa Francisco convidou a ler integralmente em sua Exortação ${ }^{21}$ - fale da questão socioambiental, o seu capítulo quarto toca especificamente no que os padres sinodais chamaram de

\footnotetext{
${ }^{15} \mathrm{RH}$ 15. Uma referência a isso também se encontra nas palavras do Sínodo dos Bispos: "Constatamos que a intervenção do ser humano perdeu seu caráter 'amigável', para assumir uma atitude voraz e predatória que tende a espremer a realidade até o esgotamento de todos os recursos naturais disponíveis" (SÍNODO DOS BISPOS, Documento Final, 71).

${ }^{16}$ SÍNODO DOS BISPOS, Instrumentum Laboris, 102.

${ }^{17}$ Isso já aparece em EG 14-15, mas, de forma particular, nos números 25-32.

${ }^{18}$ EC 6.

${ }^{19}$ SÍNODO DOS BISPOS, Instrumentum Laboris, 5.

${ }^{20}$ De fato, os cinco capítulos do Documento Final do Sínodo tomam a conversão como tema central de cada uma de suas ênfases. Fala-se, portanto, em "escuta" e "conversão pastoral" (5-19), "conversão pastoral" (20-40), "conversão cultural" (41-64), "conversão ecológica" (65-85), "conversão sinodal” (86-119).

${ }^{21}$ Logo nos primeiros parágrafos de sua Exortação Pós-Sinodal, o Papa Francisco advertiu sobre a importância do Documento Final do Sínodo, de 2019, dizendo: “Aqui não vou desenvolver todas as questões amplamente tratadas no Documento conclusivo; não pretendo substitui-lo nem repeti-lo. [...] Ao mesmo tempo, quero apresentar de maneira oficial o citado Documento, que nos oferece as conclusões do Sínodo e no qual colaboraram muitas pessoas que conhecem melhor do que eu e do que a Cúria Romana a problemática da Amazônia, porque vivem lá, por ela sofrem e a amam apaixonadamente. Nesta Exortação, preferi não citar o Documento, convidando a lê-lo integralmente" (Querida Amazônia, 2-3).
} 
Novos caminhos de conversão ecológica. Desde as primeiras páginas, reclama a importância do meio para a manutenção da vida de comunidades inteiras, alargando a concepção ecológica para além da vegetação, do clima e da fauna e considerando as culturas humanas que ali estabeleceram-se há séculos e mantêm um modelo de subsistência com ênfase ao respeito à natureza. Diz o texto: "A água e a terra desta região alimentam e sustentam a natureza, a vida e as culturas de inúmeras comunidades indígenas, camponesas, afrodescendentes (quilombolas), caboclos, assentados, ribeirinhos e habitantes dos centros urbanos". ${ }^{22}$ Desse modo, segundo nossa leitura, três eixos de ação podem ser destacados das indicações sinodais: a) a denúncia de uma cultura voraz e de morte, que atenta contra a vida em abundância para todos, movida pelo consumismo desenfreado; b) a consideração das culturas originárias, fonte legítima para descobrirmos uma nova maneira de nos relacionarmos com o ecossistema, sem prejuízo para as gerações futuras; c) a consolidação de cooperação em nível internacional e inter-religioso para projetos de preservação, como um Observatório socioambiental para a Amazônia, em parceria com instituições civis e Universidades Católicas, e a criação de um fundo econômico específico para a Amazônia, a ser gerido conjuntamente por representações eclesiásticas e civis. Nas palavras de Francisco, "o urgente desafio de proteger nossa casa comum inclui a preocupação de unir toda a família humana na busca de um desenvolvimento sustentável e integral, pois sabemos que as coisas podem mudar". ${ }^{23}$ Embora, contudo, o papa demonstre a franqueza necessária para o reconhecimento dos problemas como estão atualmente postos, concentra-se na possibilidade de conversão, de mudança de perspectivas, de construção de um mundo novo.

Isso pode ser observado no tom esperançoso com que Francisco insiste na possibilidade de união de forças pela preservação da natureza e reversão de alguns dos colapsos já em curso, sentimento que influencia diretamente a redação dos documentos emanados do Sínodo da Amazônia: “A esperança convida-nos a reconhecer que sempre há uma saída, sempre podemos mudar de rumo, sempre podemos fazer alguma coisa para resolver os problemas". ${ }^{24}$ De forma particular, trata-se do que aparece no Documento Final do Sínodo, que, de maneira geral, apresenta-se em estreita linha de continuidade com o texto da Encíclica Laudato $\mathrm{Si}^{\prime}$ - inclusive citando-a abundantemente

${ }^{22}$ SÍNODO DOS BISPOS, Documento Final, 7.

${ }^{23}$ LS 13.

${ }^{24}$ LS 61. 
nos momentos em que se toma a ecologia como foco da análise. Esse é o caso do reconhecimento de que, embora nosso planeta seja um dom de Deus, "sabemos da urgência de agir diante de uma crise socioambiental sem precedentes. Necessitamos uma conversão ecológica para responder adequadamente" ${ }^{25}$ aos desafios de nosso tempo. Nesse sentido, a conversão integral insistentemente posta desde a sua primeira evocação por Francisco, obriga a própria Teologia a repensar o lugar que ocupou ante a questão ecológica. Sabemos que muito tem sido discutido em âmbito acadêmico ${ }^{26}$ sobre os impactos de uma compreensão perversa da relação homem versus natureza, isto é, a definição do ser humano como o centro absoluto do cosmos, nas palavras de Descartes, como "senhor e possuidor"27 - ou, ainda, a instauração do imperium hominis. ${ }^{28}$ Tal concepção de mundo, contudo, colapsou, e não nos resta uma alternativa senão expandir nosso olhar, recobrando o significado positivo da obra criadora de Deus, isto é, a noção de criaturalidade para além dos limites do ser humano. Implica resgatar a compreensão de que "cada criatura reflete algo de Deus e tem uma mensagem a nos transmitir, ou a certeza de que Cristo assumiu em $\mathrm{Si}$ mesmo este mundo material e agora, ressuscitado, habita no íntimo de cada ser, envolvendo-se com o seu carinho e penetrando-o com sua luz". ${ }^{29}$

De maneira nenhuma, ao insistirmos nesse ponto pretendemos regredir a uma concepção panteísta da realidade, como se a sacralidade do mundo, como vestígio do Criador - tal como Agostinho definira ${ }^{30}$ - pudesse ser confundida com a deificação da natureza. A natureza é sagrada porque aponta para o seu Criador. Em nosso tempo, porém, clama por justiça e por uma solução, já que a

\footnotetext{
${ }^{25}$ SÍNODO DOS BISPOS, Documento Final, 65.

${ }^{26}$ Partindo do que nos é próximo, este é o caso das pesquisas desenvolvidas ao longo da última década pela professora Ivoni Richter Reimer, com ênfase para a questão ecológica de maneira precursora no Brasil. Entre outras obras, lembramos: RICHTER REIMER, I., Terra e água na espiritualidade do movimento de Jesus. Ver também RICHTER REIMER, I.; LEMOS, C. T.; ANDRADE, C. B.; CALDEIRA, R. C. (Orgs.)., Religião e Transformações Socioambientais, entre outros.

${ }^{27}$ RENÉ DESCARTES, Discurso do Método, VI parte, $\S 2$.

${ }^{28}$ FRANCIS BACON, Novum Organum, § CXXIX. Para Francis Bacon (§ CXXIX), "o império do homem sobre as coisas se apoia unicamente nas artes e nas ciências. A natureza não se domina, senão obedecendo-lhe".

${ }^{29} \operatorname{LS} 221$.

${ }^{30}$ Como recorda Agostinho em O Livre-arbítrio, "em qualquer lugar onde olhares, a sabedoria te fala pelos vestígios que imprimiu em todas as suas obras" (AGOSTINHO, O Livre-Arbítrio, III, cap. 16, § 41 - grifos nossos).
} 
inércia de nossas comunidades tem permitido o seu constante fenecer. Trata-se da imbricação de concepções paradoxais, de modo que o aprofundamento da discussão teológica sobre o tema da ecologia poderá contribuir no aclaramento de visões. Assim, será possível substituir uma postura de concorrência e oposição, pela colaboração mútua - sem a qual o prejuízo não fará concessões, alcançando-nos a todos nós, sem exceção. Nesse rumo parecem convergir tanto o magistério de Francisco, como as discussões oriundas do Sínodo da Amazônia, superando divisões e propondo um espaço em que todos os que honestamente se inclinam à reflexão sobre a temática tenham a oportunidade de oferecer a sua parcela de contribuição. É esse o ponto que faz da ecologia lugar teológico privilegiado, já que a "destruição do ambiente humano é um fato muito grave", atentando diretamente contra o mundo, criado por Deus e confiado ao homem, e, além disso, contra a vida humana, "dom que deve ser protegido de várias formas de degradação". ${ }^{31}$ De forma particular pensando o dinamismo da Igreja no Brasil, especialmente em sua presença na Amazônia, a ação pastoral se confunde com o compromisso de preservação do ecossistema, do horizonte vital de rica diversidade, adotando hábitos responsáveis que respeitem e valorizem seus povos, "suas tradições e sabedoria, protegendo a terra e mudando nossa cultura de consumo excessivo". 32

Mais que isso, entende-se como parte de uma "solidariedade internacional que deve favorecer e reconhecer o papel central" 33 que o bioma amazônico exerce para a manutenção do equilíbrio do planeta. Desse modo, se a questão da vida talvez nunca antes tivesse atingido o grau de importância que testemunhamos em nossos dias, sobretudo numa articulação profunda com os problemas ambientais, muito além da esfera simplesmente humana (já que o cuidado com o meio também incide na manutenção da vida do homem na Terra), encontramo-nos atualmente ante a seguinte bifurcação: a) o reconhecimento

\footnotetext{
${ }^{31} \mathrm{LS} 7$.

${ }^{32}$ SÍNODO DOS BISPOS, Documento Final, 84. Sobre o respeito à diversidade de saberes e à colaboração dos povos originários da Amazônia, o Sínodo dos Bispos afirmou que: "A Igreja reconhece a sabedoria dos povos amazônicos sobre a biodiversidade, uma sabedoria tradicional que é um processo vivo e sempre em andamento" (SÍNODO DOS BISPOS, Documento Final do Sínodo para a Amazônia, 76). Sobre isso, também recordo as várias vezes em que estive na Amazônia, como assessor em encontros de formação. O cuidado daquele povo com a ecologia, com a preservação do meio ambiente, demonstrado desde os pequenos gestos, como a recusa ao uso de copos e demais utensílios descartáveis, o cuidado no uso da água. Um testemunho realmente edificante.

${ }^{33}$ SÍNODO DOS BISPOS, Documento Final, 68.
} 
dos limites por nós ocasionados e b) a disposição à conversão, promovida por meio de uma ação solidária, em que a vida em sua globalidade seja o que nos une. Isso de algum modo se faz presente no que o Papa Francisco chamou de "quatro grandes sonhos para a Amazônia".

\section{Um sonho ecológico para a Igreja}

A metáfora do sonho, utilizada pelo papa na estruturação da Exortação Pós-Sinodal, ajuda-nos a outra vez conceber a tonalidade esperançosa impressa por Francisco em seu texto. Muitos esperavam um texto definitivo, resolutório de todas as conflitualidades postas em jogo pela experiência sinodal. Francisco, ao contrário, colocando-se como um irmão da humanidade inteira, especialmente no caminho de resguardo da ecologia, pondo-se, "humildemente", a "formular quatro grandes sonhos" que a Amazônia lhe inspirara. ${ }^{34} \mathrm{O}$ primeiro deles, traz para a cena a degradação social que domina as comunidades amazônicas, incluindo a realidade dos povos nativos, expropriados das condições elementares de manutenção de subsistência, forçados a arriscar a vida nos grandes centros urbanos. Restaurar o aspecto socioambiental, nesse sentido, obriga-nos a olhar, em primeiro lugar, para os direitos dos que de maneira mais próxima estabelecem uma relação vital com o ecossistema, integrando-se a ele diretamente. Disso resulta que o segundo sonho apresentado por Francisco tenha em vista a preservação das riquezas culturais que caracterizam a Amazônia. Trata-se de um projeto que se constrói em estreita sintonia com o terceiro grande sonho, a custódia do patrimônio natural presente em rios e florestas, plantas e animais, para que a vida transborde em plenitude e para todos. Enfim, em quarto lugar, o papa também faz referência à riqueza eclesial expressa pelas centenas de milhares de comunidades cristãs em solo amazônico, de forma que sejam capazes de encarnar o Evangelho de Cristo em suas terras, qual fonte que poderá rebentar novos impulsos para a Igreja. Note-se como cada um dos sonhos apenas possui sentido na medida em que está imbricado nos outros, num processo de articulação que visa a estabilização de nossa relação com o planeta, pela via da natureza, mas também a reorientação do sentido da vida humana. ${ }^{35}$ Assim sendo, o texto da Exortação vai pouco a pouco diluindo a intuição colhida dos

\footnotetext{
${ }^{34}$ Querida Amazônia, 6.

${ }^{35}$ Querida Amazônia, 7.
} 
sonhos de Francisco em orientações pastorais, encorajamento, e até mesmo algumas provocações, para que nos tornemos capazes de realizá-los entre nós. $\mathrm{O}$ fato de se expressarem como sonhos não quer dizer que se reduzam a abstrações oníricas, a elucubrações descoladas do solo concreto em que a vida transcorre. Sonhos aqui são como metas a serem alcançadas num itinerário conjunto. Sonhos que darão lugar a novos sonhos, sempre intermediados pelas conquistas que ensejam.

Além disso, ainda como endosso à conversão sinodal, isto é, à composição de um novo paradigma eclesiológico impulsionado pela experiência amazônica, não podemos deixar de mencionar o modo como Francisco aborda a questão ecológica na Exortação Querida Amazônia, um elemento comum também a outros textos emanados de seu pontificado. Em geral, os documentos magisteriais possuem o que aqui podemos chamar de hermenêutica da continuidade. A cada novo escrito, explicita-se a relação contínua do magistério, evocando a palavra de autoridades da fé, como é o caso dos padres dos primeiros séculos do cristianismo, bem como a comunhão com o ensinamento dos últimos pontífices. ${ }^{36}$ Nesse quesito, a Exortação de Francisco não é diferente. Não obstante, também é capaz de imprimir certa atualização ao modo de refletir já experimentado pela Igreja. Aqui destacamos as constantes inserções interpostas pelo papa em seu texto, colhidas diretamente da experiência latino-americana. É o caso do uso da poesia, da confrontação com o que é explanado a partir da experiência de missionários e missionárias que devotaram suas vidas à evangelização da Amazônia, da indicação de dados científicos, de fragmentos literários de autores com reconhecimento mundial, de vivências comunitárias da fé cristã, da sabedoria indígena colhida através de registros transcritos, e de outras fontes mais, todas tendo em comum o fato de seus autores serem protagonistas da vida na América Latina. ${ }^{37}$ Este é o caso, por exemplo, das referências a Ana Varela Tafur, Jorge Vega Márquez, Alberto C. Araújo, Ramón Iribertegui, Amarílis Tupiassú, Frederico Benício de Sousa Costa, Yana Lucila Lema, Evaristo Eduardo de Miranda, Juan Carlos Galeano, Javier Yglesias, Mario Vargas Llosa, Euclides da Cunha, Pablo Neruda, Amadeu Thiago de Mello,

\footnotetext{
${ }^{36}$ Tanto Bento XVI quanto João Paulo II são abundantemente citados por Francisco em sua Exortação.

${ }^{37} \mathrm{Na}$ América Latina, o protagonismo dos leigos pode ser notado especialmente nas diferentes expressões do catolicismo popular. Ver, por exemplo MARTINS FILHO, J. R. F., Sobre o protagonismo laical do catolicismo popular.
} 
Vinícius de Moraes, Harald Sioli, Sui Yun e Pedro Casaldáliga - esse último, bispo emérito da Prelazia de São Felix do Araguaia, perseguido e ameaçado de morte pela sua constante luta em defesa dos povos indígenas. Outra vez tratase, segundo nossa impressão, de um forte indício de que a tarefa de resguardo da Amazônia, em seu potencial ecológico e de impacto socioambiental, deve ser um compromisso primeiramente assumido pelos próprios agentes latinoamericanos. Tal constatação certamente também impacta sobre o modelo de Igreja que se tem em mente, uma Igreja colaborativa, em estreito vínculo de comunhão, mas que também aposta na autonomia de suas partes, isto é, no modelo sinodal como um imprescindível componente da catolicidade.

Os dois primeiros capítulos da Exortação concentram-se no que Francisco denominou como um sonho social e cultural para a Amazônia. Principiando pelas demandas sociais e existenciais da região amazônica, dão a entender que a problemática ambiental não está desatrelada da condição de vida dos sujeitos que se estabeleceram naquele território. Por um lado, diz o papa, tratase do sonho "duma Amazônia que integre e promova todos os seus habitantes, para poderem consolidar o 'bem viver". ${ }^{38}$ A primeira e mais evidente consequência das constantes crises propaladas em território amazônico é a degradação das condições de vida e a marginalização de suas populações, postas aquém dos requisitos básicos de subsistência. Este fator desencadeia um círculo vicioso entre as precárias condições de vida dos habitantes, e o desgaste das fontes naturais, cujo descuido se torna ainda mais acirrado. Sem melhores condições de moradia, por exemplo, muitas famílias arranjam-se como podem nas encostas dos rios, lançando dejetos em seus leitos. Esta é a realidade das grandes metrópoles da Amazônia, que contrastam a beleza natural e a riqueza dos tempos de exploração com os altos índices de pobreza dos dias atuais. Esse círculo, como dissemos, torna-se vicioso na medida em que o aprofundamento da falta de condições de subsistência força uma maior exploração e destruição das fontes naturais. Como consequência, quanto mais se fragiliza a manutenção da vida, pela falta de assistência mínima em termos de saúde e educação, mas também pela impossibilidade de extração de alimento e água limpa, mais indígenas e ribeirinhos são forçados a migrar para os ambientes urbanos, num ciclo cujo termo não pode ser vislumbrado proximamente. É, portanto, preciso romper com essa corrente, de modo que o adequado tratamento das questões sociais incidirá positivamente sobre o

$\overline{{ }^{38} \text { Querida Amazônia, } 8 .}$ 
problema ecológico. Este desafio também passa pela reformulação de políticas culturais que valorizem os povos autóctones, dando-lhes o necessário para a continuidade de suas tradições. Como recorda o Papa Francisco, promover a Amazônia não "implica colonizá-la culturalmente, mas fazer de modo que ela própria tire fora o melhor de si mesma". Ainda nas palavras do papa, deve-se "cultivar sem desenraizar", "fazer crescer sem enfraquecer a identidade" e "promover sem invadir". ${ }^{39}$ Outra vez aposta-se na capacidade dos habitantes locais de continuarem a cuidar do patrimônio que por tantos séculos souberam resguardar, mas que, dado os avanços da técnica e do mercado, hoje correm o risco de simplesmente deixar de existir.

Enfim, a partir de nosso foco neste texto não é possível desvincular a questão ambiental/ecológica do que dissemos sobre os aspectos sociais e culturais. Isso é o que fica claro no capítulo terceiro da Exortação Querida Amazônia, em que o papa põe em evidência o seu sonho ecológico. Para uma "realidade cultural como a Amazônia, onde existe uma relação tão estreita do ser humano com a natureza, a vida diária é sempre cósmica. Libertar os outros das suas escravidões implica certamente cuidar do meio ambiente e defendê1o". ${ }^{40}$ Eis, portanto, uma vez mais o sentido que as questões ecológicas adquirem - a partir da nova perspectiva aberta por Francisco para toda a Igreja - de um debate socioambiental mais amplo, que envolverá o diálogo com outras denominações cristãs e a aproximação inter-religiosa, a cooperação internacional, especialmente dos países que dividem o território amazônico iniciativas essas sempre conjugadas com a "sabedoria ancestral" dos povos da Amazônia, procurando "intervir de forma sustentável, preservando ao mesmo tempo o estilo de vida e os sistemas de valores dos habitantes". ${ }^{41}$ Tanto o pontificado de Francisco, quanto o recente acontecimento sinodal, dão, pois, à Igreja a oportunidade de pôr-se numa das discussões mais urgentes de nosso tempo, sem a qual estaremos fadados ao colapso. A realidade amazônica, desse modo, oferece-nos não apenas pistas de ação para o tratamento de um caso isolado, mas condições de estendermos nossas iniciativas para outras partes do globo que também sofrem as consequências da exploração desmedida e da falta de cuidado com o meio ambiente.

Por muito tempo se falou em crise humanitária, sem, contudo, perceber que a questão ambiental/ecológica é um dos epicentros das grandes transformações

\footnotetext{
${ }^{39}$ Querida Amazônia, 28.

${ }^{40}$ Querida Amazônia, 41.

${ }^{41}$ Querida Amazônia, 51.
} 
operadas no planeta desde o último século. Estamos no ponto de passagem de uma cosmovisão para outra, na consolidação de um novo formato a partir do qual nos relacionamos com a natureza. Ao contrário de outras épocas, dessa vez o ser humano tem a oportunidade de participar positivamente das transformações, com consequências que poderão se alastrar até as próximas gerações (e que o vindouro seja promissor!). Ao trazer a Igreja para este cenário, Francisco certamente colabora com o despertar de discussões que, ancoradas na problemática ecológica, desafiam a Teologia em sua estrutura de análise do mundo, para não dizer das novas possibilidades eclesiais que irão eclodir. As novas gerações são, desse modo, um alvo que não pode ser desprezado, motivo pelo qual o resgate da discussão socioambiental não deve caminhar alheio de um projeto educativo com ênfase na consolidação de bons hábitos ecológicos. Como disse o papa, "a grande ecologia sempre inclui um aspecto educativo, que provoca o desenvolvimento de novos hábitos nas pessoas e nos grupos humanos". ${ }^{42}$ A cultura do descarte e do consumismo, já internalizada em boa parte da sociedade atual, deverá dar lugar a uma política sustentável e transformadora, que saiba respeitar o meio ambiente, estabelecendo com ele uma relação de fraternidade. A figura de Francisco de Assis, santo patrono da ecologia, torna-se outra vez modelo, agora para a Igreja no terceiro milênio: a fraternidade estendida a toda a criação, da qual o homem é partícipe, não ator solo. Com este ensinamento, emanado da tradição franciscana e estendido pela via de um pontificado aberto a pequenas transformações, damos por satisfeita nossa breve incursão, a respeito da qual apenas gostaríamos de recordar alguns pontos.

\section{Conclusão}

Ao término de nosso percurso, creio ter apontado suficientes argumentos em favor do vigor ecológico que continuamente tem impulsionado o magistério de Francisco, desde a Encíclica Laudato Si 'até a Exortação Querida Amazônia. No entanto, à guisa de conclusão, de tudo o que dissemos é possível extrair dois ensinamentos. Na verdade, sobre a questão ecológica, pontualmente instaurada por Francisco, estamos seguros de tratar-se de um tema que, para além de seu pontificado, alcançará as gerações vindouras. Nesse sentido, esperamos vivamente que o tratamento

${ }^{42}$ Querida Amazônia, 58. 
dado ao problema socioambiental neste momento da humanidade ajude a aplacar algumas das consequências que eventualmente recairiam sobre o planeta, o que assumimos como endosso ao espírito de esperança com que o papa sempre escolheu tocar os problemas ambientais. Os pontos que seguem procuram, portanto, articular a questão ecológica e/ou ambiental à tarefa da Teologia, seja por seu potencial reflexivo, seja pela práxis pastoral dela resultante.

Primeiramente, são inegáveis a importância e o impacto causados por Francisco no tocante às questões socioambientais. Desde o início de seu pontificado, um lugar especial tem sido concedido à ecologia. Por um lado, valendo-se da inspiração franciscana de sua missão apostólica: uma Igreja aberta às fragilidades existenciais e materiais do tempo presente. Por outro, dado o aguçamento das crises naturais, que pela primeira vez na história do planeta adquiriram um nível alarmante, como efeito das iniciativas de destruição propaladas pelo próprio ser humano. É preciso, por isso, resgatar a indissociabilidade entre a condição humana e o meio ambiente em que desenvolve sua vida. Aliás, muitos teóricos do pensamento contemporâneo ${ }^{43}$ alertaram sobre a inviolabilidade entre homem e meio, sobre os limites impostos ao desenvolvimento da humanidade, sempre implicados na conservação das fontes naturais - embora essas tenham sido por tanto tempo tomadas simplesmente como recursos disponíveis ao uso desmedido. A Igreja, como portadora da mensagem salvífica de Cristo, não pode alienar-se da responsabilidade de exortar e convocar a uma transformação radical, o que certamente também passa pelo resgate de uma concepção mais abrangente do lugar do homem na obra da criação e do seu senhorio sobre a natureza. Por muito tempo confundira-se ser senhor com ser proprietário absoluto. Ao contrário, não podemos nos esquecer que a dignidade da criatura possui um vínculo de dependência com sua procedência, a perfeição do Criador. Enquanto custódio da criação, o homem tem um papel fundamental, zelando pelo que lhe foi confiado e prestando contas do seu trabalho Àquele de quem o recebera. Trata-se de um pressuposto fundamental, constantemente reforçado pela tradição teológica e, além disso, incompatível com a lógica do consumo e

\footnotetext{
${ }^{43}$ Hannah Arendt, por exemplo, logo na abertura de sua obra A Condição Humana (de 1958), destaca o estreito vínculo entre o ser humano e o seu habitat, isto é, o Planeta Terra. O rompimento dessa relação implicaria numa recomposição das leituras que possuímos a respeito da condição humana. (ARENDT, H., A Condição Humana, p. 4-10).
} 
da destruição impulsionada de maneira frenética. Somente através de uma rediscussão da criaturalidade, considerando toda a obra criada como objeto de uma doação originária do Criador, há de ser entendido que não há outra postura esperada da humanidade senão o cuidado. Este é o cuidado com a "Casa Comum", ${ }^{44}$ insistentemente solicitado pelo Papa Francisco desde a Laudato Si'e, mais recentemente, pela Querida Amazônia. Em termos da questão ecológica, trata-se de um legado sem precedentes para a Igreja e para o mundo.

Além disso, também não podemos desprezar o valioso ensinamento posto em jogo desde a postura adotada por Francisco no tratamento do tema, até as constantes indicações textuais distribuídas ao longo dos vários documentos emanados do Sínodo da Amazônia - bem como de outros momentos de seu pontificado. Aqui damos realce para a dimensão sinodal da Igreja, que não significa a compartimentalização de problemáticas relegadas unicamente ao alcance dos que as padecem. Ao mesmo tempo, também não constitui a imposição de modelos e respostas prontas, advindas de realidades humanas, sociais e ecológicas tão distintas. Ao sinalizar sua preocupação com a realidade amazônica, Francisco transmite o sentimento de toda a Igreja diante da degradação da floresta e do desrespeito aos seus povos ancestrais. Quanto às soluções esperadas, expressa-as a partir de grandes eixos de ação - por ele chamados de sonhos - os quais não poderão concretizar-se senão tomando como ponto de partida a eclesialidade local, a criatividade movida pelo Espírito em busca de respostas efetivamente novas, condizentes com a nova realidade que se impõe. Em termos teológicos, tal ênfase sinodal abre-nos os olhos para a constituição de um novo modelo eclesial, uma eclesialidade cujas raízes devem aprofundar-se nas culturas locais, legitimamente constituídas a partir da comunhão que exercem para com a Igreja universal, sem que isso signifique limitá-las a fórmulas gerais, a processos que prescindam da participação dos locais, à subjugação em função dos grandes centros teológicos mundiais. Trata-se, a meu ver, de uma via de mão dupla, da Amazônia para a toda a Igreja e de toda a Igreja para a Amazônia, tendo no debate sobre a questão ecológica o ponto de unidade para a reflexão e a ação. Em suma, isso é o que está em jogo no sonho ecológico para a Igreja.

${ }^{44}$ LS 13. 


\section{Referências bibliográficas}

AGÊNCIA BRASILEIRA DE INTELIGÊNCIA. Nota de Esclarecimento. Disponível em: <http://www.abin.gov.br/gsi-esclarece-que-a-igreja-catolicanao-e-objeto-de-qualquer-tipo-de-acao/> . Acesso em: 07 fev. 2020.

AGOSTINHO. O livre-arbítrio. 1.ed. São Paulo: Paulus, 1995. (Patrística, 8).

ALMEIDA, N. M.; BRIGHENTI, A. Sínodo da Amazônia: novos caminhos para a Igreja e para uma ecologia integral. Revista Pistis Praxis, v.11, n.3, p. 617-640, set./dez. 2019.

ARENDT, H. A condição humana. 13.ed. Rio de Janeiro: Forense Universitária, 2017.

A12 REDAÇÃO. Papa Francisco fala sobre imagens jogadas no Rio Tibre. Disponível em: <https:/www.a12.com/redacaoa12/igreja/papa-franciscolamenta-imagens-roubadas-e-jogadas-no-rio-tibre>. Acesso em: 10 fev. 2020. BRIGHENTI, A. O Sínodo da Amazônia: o evento e seus resultados. REB, v.79, n.314, p. 591-614, set./dez. 2019.

FRANCIS BACON. Novum Organum ou Verdadeiras indicações acerca da interpretação da natureza. São Paulo: Nova Cultural, 2005.

FRANCISCO, PP. Carta Encíclica Laudato Si' - sobre o cuidado da casa comum. Disponível em <http://www.vatican.va/content/francesco/pt/ encyclicals/documents/papa-francesco_20150524_enciclica-laudato-si.html> Acesso em: 12 jan. 2020.

FRANCISCO, PP. Constituição Apostólica Episcopalis Communio sobre o Sínodo dos Bispos. Disponível em: <http://www.vatican.va/content/ francesco/pt/apost_constitutions/documents/papa-francesco_costituzioneap_20180915_episcopalis-communio.html> Acesso em: 20 jan. 2020.

FRANCISCO, PP. Encontro com a população - discurso do Santo Padre. Visita Apostólica do Papa Francisco ao Chile e Peru. Puerto Maldonado, 19 de janeiro de 2018. Disponível em: <http://w2.vatican.va/content/francesco/ pt/speeches/2018/january/documents/papa-francesco_20180119_perupuertomaldonado-popolazione.html>. Acesso em: 17 fev. 2020.

FRANCISCO, PP. Exortação Apostólica Evangelii Gaudium - sobre o anúncio do Evangelho no mundo actual. Disponível em: $<$ http://www. vatican.va/content/francesco/pt/apost_exhortations/documents/papa- 
francesco_esortazione-ap_20131124_evangelii-gaudium.html > Acesso em: 15 jan. 2020.

FRANCISCO, PP. Exortação Apostólica Pós-Sinodal Querida Amazonia ao povo de Deus e a todas as pessoas de boa vontade. Disponível em: $<$ http:// www.vatican.va/content/francesco/pt/apost_exhortations/documents/papafrancesco_esortazione-ap_20200202_querida-amazonia.html>. Acesso em: 12 fev. 2020.

FRAZÃO, F. CNBB vai na "contramão" de propostas de governo Bolsonaro. Estadão, São Paulo, 12 fev. 2020. Disponível em: <https://brasil.estadao. com.br/noticias/geral,cnbb-vai-na-contramao-de-propostas-do-governobolsonaro,70003195088>. Acesso em: 17 fev. 2020.

JOÃO XXIII, PP. Allocuzione del Santo Padre Giovanni XXIII con la quale annuncia il Sinodo Romano, il Concilio Ecumenico e l'aggiornamento del Codice di Diritto Canonico. 1959. Disponível em: <http:/www.vatican.va/ content/john-xxiii/it/speeches/1959/documents/hf_j-xxiii_spe_19590125_ annuncio.html>. Acesso em: 12 fev. 2020.

JOÃO PAULO II, PP. Carta Encíclica Redemptor Hominis. Disponível em: $<$ https://www.google.com/search?q=redemptoris + hominis\&oq=redemptoris +hominis \&aqs $=$ chrome..69i57j017.3199j $1 \mathrm{j} 4 \&$ sourceid $=$ chrome $\& \mathrm{ie}=\mathrm{UTF}-8>$. Acesso em: 15 fev. 2020.

MARTINS FILHO, J. R. F. Sobre o protagonismo laical do catolicismo popular: pistas para reflexão. REB, v.78, n.311, p. 679-694, set./dez. 2018.

RENÉ DESCARTES. Discurso do Método. São Paulo: Nova Cultural, 2000. RICHTER REIMER, I. Terra e água na espiritualidade do movimento de Jesus: contribuições para um mundo globalizado. São Leopoldo: Oikos; Goiânia: Ed. da PUC Goiás, 2010.

RICHTER REIMER, I.; LEMOS, C. T.; ANDRADE, C. B.; CALDEIRA, R. C. (Orgs.). Religião e Transformações Socioambientais. Caminhos, v.17, n.3, p. 05-103, 2019.

SENADO FEDERAL. Humberto Costa critica interferência da Abin na Igreja Católica. Disponível em: <https://www12.senado.leg.br/noticias/ materias/2019/02/12/humberto-costa-critica-interferencia-da-abin-na-igrejacatolica >. Acesso em: 08 fev. 2020.

SILVEIRA, E. J. S.; REIS, M. V. F.; ALMEIDA, F. P. M. O Sínodo da 
Amazônia e os dilemas do catolicismo. Revista Pistis Praxis, v.11, n.3, p. 669-691, set./dez. 2019.

SÍNODO DOS BISPOS. Assembleia Especial para a Região Pan-Amazônica. Amazônia: novos caminhos para a Igreja e para uma ecologia integral. Documento Final. Disponível em: <http://www.vatican.va/roman_curia/ synod/documents/rc_synod_doc_20191026_sinodo-amazzonia_po.html >. Acesso em: 20 nov. 2019.

SÍNODO DOS BISPOS. Assembleia Especial para a Região Pan-Amazônica. Amazônia: novos caminhos para a Igreja e para uma ecologia integral. Instrumentum Laboris. Edições CNBB, 2019.

SOARES, I. Bolsonaro critica texto do Papa: o papa é argentino, mas Deus é brasileiro. O pontífice pediu proteção da floresta amazônica em texto. Correio Brasiliense, Brasília, 13 fev. 2020. Disponível em: <https:// www.correiobraziliense.com.br/app/noticia/politica/2020/02/13/interna politica, 827812 /bolsonaro-critica-texto-do-papa-o-papa-e-argentino-masdeus-e-brasil.shtml>. Acesso em: 16 fev. 2020.

\section{José Reinaldo F. Martins Filho}

Doutor em Ciências da Religião pela Pontifícia Universidade Católica de Goiás Docente no Programa de Pós-Graduação em Ciências da Religião pela Pontifícia Universidade Católica de Goiás Goiânia / GO - Brasil E-mail: jreinaldomartins@gmail.com

Recebido em: 20/02/2020

Aprovado em: 03/04/2020 